\title{
EDUCAÇÃO (FÍSICA) E ESPORTE: NAS TEIAS DE UMA PESQUISA-AÇÃO EXTENSIONISTA EM UMA UNIVERSIDADE PÚBLICA BAIANA
}

\author{
EDUCATION (PHYSICAL) AND SPORT: ON THE WEBS AN ACTION \\ RESEARCH EXTENSION IN A UNIVERSITY PUBLIC BAIANA \\ EDUCACIÓN (FÍSICA) Y DEPORTE: EN LAS WEBS UNA INVESTIGACIÓN \\ ACCIÓN DE EXTENSIÓN DE UNA UNIVERSIDAD PÚBLICA BAIANA
}

\author{
Jaderson Silva Barbosa*, Miguel Almir Lima de Araújo*
}

Palavras-chave

Educação.

Esportes.

Pesquisa qualitativa.

Pesquisa

participativa

baseada na

comunidade.
Resumo: Este estudo é parte de uma Pesquisa-Ação extensionista que envolveu a formação esportiva e cidadã de jovens moradores de bairros circunvizinhos a UEFSBA. A Pesquisa e a Ação propuseram, sem fazer entrincheiramentos epistemológicos, a utilização de referenciais teóricos da área da Educação Física e Esporte para um diálogo com os dados da realidade, especialmente, a partir de contribuições dos atores e autores envolvidos. Esses dados foram sintetizados a partir da técnica do Discurso do Sujeito Coletivo e através dos resultados pôde-se perceber que é possível propor transformação social, contudo, reconhecendo as limitações no que diz respeito à amplitude das mudanças e, neste sentido, as experiências teóricas e vivenciais, trouxeram elementos que propõem rupturas em dimensões micro (proposta pedagógica) e macroestruturais (políticas públicas), ambas permanentemente entrelaçadas.

\section{Keywords:}

Education. Sports.

Qualitative research.

Community-based

participatory

research

\begin{abstract}
This study was an extension Action Research involving sports training and civic education of young residents of surrounding UEFS-BA neighborhoods. The Research and Action proposed, without epistemological entrenchments, the use of theoretical frameworks in the field of Physical Education and Sport for a dialogue with the realily data, especially from contributions of actors and authors involved. These data were synthesized using the technique of the Collective Subject Speech. Through the results of this study could be seen that it is possible to propose social change, however, recognizing the limitations related to the magnitude of the changes. And in that meaning, the theoretical and experiential experiences brought elements that suggest disruptions in the micro dimensions (pedagogical proposal) and macrostructural (public policy) and that those are permanently intertwined.
\end{abstract}

Resumen: Este estudio fue una extensión de Investigación Acción que incluya una formación deportiva y educación cívica de los jóvenes residentes de los barrios que rodean UEFS - BA. Investigación y Acción propuesto, sin atrincheramientos epistemológicos, la utilización de marcos teóricos en el campo de la Educación Física y el Deporte para el diálogo con los datos reales, sobre todo de los testimonios y las contribuciones de los actores y autores involucrados, éstos sintetiza a partir de la técnica del Discurso del Sujeto Colectivo. Podría ser visto que es posible proponer cambio social, sin embargo, reconocer las limitaciones con respecto a la magnitud de los cambios. En este estudio, se ha considerado a pesar de que, los teóricos y vivenciales, experiencias trajeron elementos que sugieren alteraciones en micro dimensiones ( propuesta pedagógica ) y macro - estructurales (políticas) que se entrelazan de forma permanente.
*Universidade Estadual de Feira de Santana. Feira de Santana, BA, Brasil. E-mail: jsbesportescontato@gmail.com

Recebido em: 30-06-2014

Aprovado em: 23-01-2015

(c) (1) (8) Licence 


\section{INTRODUÇÃO}

O esporte, como manifestação da cultura corporal, compreendido dentro do contexto histórico, político, econômico e social, é, ao mesmo tempo, produto e processo cultural, não podendo, portanto, ser personificado e nem analisado de maneira fragmentada e/ou isolada.

Através da mídia, especialmente, nos acostumamos a ouvir frases como: o esporte retira das drogas; o esporte promove saúde; o esporte oportuniza ascensão social; o esporte promove a paz. Ou no caminho oposto: o esporte mata; o esporte promove exclusão. Estes e outros discursos repercutem em projetos sociais, nas universidades, nas ruas etc.

Ao reconhecer o esporte como uma produção cultural, compreendemos que o mesmo expressa atitudes humanas, que podem representar inclusão ou exclusão, transformações ou reproduções que, no mundo contemporâneo, refleti na valorização da quantificação, dos records, da consagração dos mais adaptados fisicamente, estabelecendo estereótipos de corpo e de padrões de condutas corporais/morais que, em geral, servem pra alimentar uma indústria que vive e incentiva uma inquietude humana consumista.

Mas este mesmo esporte pode ser oportunizado e direcionado como um possibilidade de resistência, uma expressão da cultura corporal que reinventa-se constantemente. Desta forma, torna-se também um instrumento de formação e diversão humana, uma alternativa contra-hegemônica, por exemplo, aos modelos sociais e econômicos vigentes.

O debate sobre o esporte e suas implicações sociais não é o tema central e isolado desta produção, contudo, atravessa todas as discussões possíveis de observação e que foram registrados nos resultados de uma pesquisa e de uma ação desenvolvida na Universidade Estadual de Feira de Santana - Bahia tendo como objeto de estudo o Projeto Escola de Esportes do PEAC - Programa Encaminhar Ação Cidadã (uma extensão universitária).

Nesta produção, uma síntese da dissertação de mestrado em educação, buscase destacar que em projetos socioeducativos esportivos, como o PEAC, existem outras possibilidades de compreensão da importância do esporte, especialmente, para denunciar problemas sociais e não para legitimar estes problemas; para promover cidadania e não reforçar processos excludentes e discriminatórios; para ser uma ação lúdica e não uma mercadoria a serviço de poucos; e para contribuir com a formação acadêmica e humana dos envolvidos no programa e não como instrumento de alienação.

Os novos conhecimentos produzidos ao longo desta intervenção e as ações encaminhadas pelo PEAC, pelos autores e atores envolvidos propõem uma aproximação entre o saber e a ação, conduta identificada pelo olhar da metodologia da Pesquisa-Ação. Assim, a construção dos problemas que direcionaram o desenvolvimento deste tipo de pesquisa foi de ordem prática, identificada e sugerida conjuntamente entre pesquisadores e participantes da comunidade, e, neste estudo, seguiram na direção de identificar se era possível uma ação extensionista oferecer subsídios aos atores/autores, especialmente os estudantes universitários envolvidos enquanto bolsistas, para a sua formação esportiva, humana, cidadã e acadêmica? É possível transformar a realidade na qual o programa estava inserido?

$\mathrm{Na}$ análise e discussões serão apresentados elementos que respondem a estas questões problematizadoras que em parte caracterizam as ações do Programa Encaminhar Ação Cidadã (PEAC) - Projeto Escola de Esporte (objeto de estudo e relato desta produção). 
Problemáticas que foram construídas por autores e atores imbricados no campo vivencial, alicerçadas com as discussões fundamentadas na literatura que discorrem sobre as temáticas do esporte e de ações extensionistas.

$\mathrm{Na}$ conclusão está destacado que, a partir das experiências com o PEAC (o projeto Escola de Esportes), foram identificados elementos que propõem rupturas e contribuições em dimensões micro (um novo olhar para compreensão da crítica ao esporte) e macroestruturais (políticas públicas e a extensão universitária), que estão entrelaçadas em uma teia complexa e diversa na qual está inserido o ser humano nos tempos atuais.

\section{EDUCAÇÃO (FÍSICA) E ESPORTE: TENSIONAMENTOS CRÍTICOS PARA UMA AÇÃO EXTENSIONTA}

Na década de noventa, os livros Metodologia do Ensino da Educação Física (SOARES, 1992) e Transformação Didático-Pedagógica do Esporte (KUNZ, 2001) foram publicados e tornaram-se obras clássicas que orientavam profissionais e estudantes, especialmente nos espaços onde se compreendia o ensino do esporte para além dos aspectos instrumentais do saber fazer, da dimensão apenas técnica, tática e da aptidão física.

Este esporte, como produção humana, é uma das manifestações da cultura corporal que deve ser tratada pedagogicamente pela área de conhecimento da Educação Física em espaços escolares e não escolares. Um fenômeno multifacetado com imbricações no campo social, econômico, político, cultural, que, na atual conjuntura, em geral, quando não é negado, em diversos espaços, direciona-se a atender ao pensamento hegemônico, à lógica do consumo, e/ou ainda como moeda de troca. Este último contexto que envolve, por exemplo, interesses de políticos em época de campanha eleitorais.

Divergir e romper com essa lógica alienante pode contribuir para a formação de uma atitude crítica, criativa e reflexiva, possibilitando às futuras gerações, propor caminhos alternativos, transformadores, mais humanos. Até porque é condenável o modelo de crescimento mundial proposto para a sociedade, que, em geral, está baseado e "[...] medido pelo aumento da produção material, e não de serviços com lazer, saúde e educação" (BAUMAN, 2013, p. 88) e aí deve-se inserir também as práticas esportivas.

É pela educação (inclusieve através do esporte) e em várias outras frentes que devemos (re)começar, pois, esta pode provocar rupturas cada vez mais profundas e radicais nos modelos propostos pelo sistema hegemônico que se apropriam de produções e sensações humanas, transformando tudo em lucro e rendimentos.

Precisamos seguir numa direção contrária, com um repertório mais amplo e plural para a compreensão da educação cidadã através do esporte. Educação que possui em sua expressão latina a palavra educere que conota tirar para fora de, conduzir, levar e criar uma iniciação aos sentidos humanos, de modo teórico e vivencial (ARAÚJO, 2008) e que compõe uma teia de aprendizados. Estes, que se acreditarmos possível, será construído historicamente, tecidos na constituição biocultural da condição humana.

De fato, o esporte está integrado com a necessidade capitalista (situação vista também em sistemas dito socialistas), estando relacionado com uma série de conjunturas que recebem muitas críticas por diversas correntes teóricas da Educação Física e que configuram uma 
nova ordem alicerçada "[...] em dimensões (ou valores) como competitividade, produtividade, secularização, igualdade de oportunidades, supremacia do mais hábil, especialização de funções, quantificação de resultados e fixação de regras" (FRANCO JUNIOR ${ }^{1}$ apud MELO et al., 2013, p. 84).

Entretanto, muitas destas críticas deveriam voltar-se, na verdade, ao sistema capitalista e não contra o esporte. Nos diversos centros de formação no ensino superior pelo Brasil, em suas diversas frentes (ensino, pesquisa e extensão), numa visão eurocêntrica da história, a partir da lógica burguesa da sociedade inglesa do século XVIII, foi construida uma compreensão do esporte unilateral, apenas a partir de um olhar midiático, mercadológico, ideológico e que, por muitas vezes, o colocou numa posição inferior, um inimigo da humanidade.

Mesmo que reconheçamos o esporte embebecido desta conjuntura alienante e desumana, penso que os profissionais da área de Educação Física devem ir além desta perspectiva unilateral, entendendo a "[...] necessidade de compreender este esporte a partir do homem que faz o esporte" (SILVA, 2009, p. 35). Ao demarcar esta posição se amplia os olhares sobre esta manifestação da cultura corporal, a partir de suas diversas possibilidades e expressões culturais, fomentando espaços de resistência, como, por exemplo, em projetos socioeducativos esportivos.

A prática esportiva deve ser compreendida com uma possibilidades de gerar espaços de resistência (no sentido de preservar tradições e propor reinvenções), capaz de despertar sensações que, por muitas vezes, são impossíveis de explicar por teorias (só vivenciando para saber).

O discurso da "curvatura da vara"2, tão divulgada pelos que defendem posições extremistas, geralmente carregadas de verticalização teórica e ideológica, talvez não atentou-se para a diversidade, do direito/condição ao ser humano a reinventar-se (inclusive as suas próprias produções), e a questionar (vivenciando) em seu tempo e nas condições possíveis, aquilo que está implicado nas relações humanas expressas nas diversas culturas.

Construir um pensamento crítico exige mais que a crítica, solicita uma "disposição ou capacidade de discutir os vários lados de uma concepção qualquer" (SODRÉ, 2012, p. 18). Destacamos, desta forma, que para um diálogo crítico proposto sobre Educação (Física), esporte e projetos sócioeducativos, foram utilizadas nesta produção, fundamentações teóricas que contribuíram com o processo de compreensão das temáticas mencionadas, sem, contudo, fazer entrincheiramentos epistemológicos.

A idéia é abrir novas possibilidade de fazer a crítica ao que está posto, especialmente na compreensão do esporte, na sua relação com projetos sociais e com o seres humanos envolvidos neste contexto. Para isto, nós siguimos na direção do pensamento de Condé (2002) que, em seu texto, De Galileu a Armstrong: as várias faces da Lua, ressalta a importância de nos destituirmos da ideia de uma certeza última para a interpretação do ser humano, ressaltando ainda que "não há profundas diferenças entre a lua de Aristóteles, a lua de Galileu, a lua de Armstrong e mesmo, sob certo aspecto, a lua do poeta, uma vez que essas interpretações existem para nós, enquanto humanos, a partir de nossa antropológica capacidade cognitiva" (CONDÉ, 2002, p. 56).

A intenção dos educadores do esporte deveria ser, dentre outras possibilidades, a de materializar o seu ensino propondo uma vivência lúdica e educativa a partir dos elementos

1 FRANCO JUNIOR, Hilário. A dança dos deuses: futebol, cultura, sociedade. São Paulo: Companhia das Letras, 2007.

2 Curvatura da Vara. Teoria enunciada por Lênin, que ao "ser criticado por assumir posições radicais e extremistas responde o seguinte: quando a vara está torta, ela fica curva de um lado e se você quer endireitá-la, não basta colocá-lo na posição correta. É preciso curvá-la para 
que envolvem a prática esportiva, propondo uma reflexão crítica do esporte sem, no entanto, negá-lo. E assim

[...] reconhecê-lo como uma atividade corporal historicamente criada e socialmente desenvolvida em torno de uma das expressões da subjetividade do homem, o jogo lúdico, que não pretende resultados materiais. [...]. No jogo praticado pela satisfação de interesses subjetivos - lúdicos - o produto da atividade é o prazer dado pela própria satisfação dos mesmos (ESCOBAR ${ }^{3}$ apud SOUZA JÚNIOR, 2011, p. 398).

Para o esporte ser uma prática educativa que atenda a interesses subjetivos, que contribuir na formação de sujeitos críticos e capazes de promover a cidadania precisamos ensiná-lo. Conscientes que nesta ação os educadores não devem desconsiderar os fatores sociais, políticos e econômicos, mas deve ir além, propor espaços vivenciais de resistência, como exemplo programas de extensão universitária que amplia o acesso ao esporte e suas múltiplas possibilidades vivenciais.

A extensão universitária é um processo acadêmico que é indissociável do ensino e da pesquisa e

[...] Nessa perspectiva, o suposto é que as ações de extensão adquirem maior efetividade se estiverem vinculadas ao processo de formação de pessoas (Ensino) e de geração de conhecimento (Pesquisa). No que se refere à relação Extensão e Ensino, a diretriz de indissociabilidade coloca o estudante como protagonista de sua formação técnica - processo de obtenção de competências necessárias à atuação profissional - e de sua formação cidadã - processo que lhe permite reconhecer-se como agente de garantia de direitos e deveres e de transformação social. (FÓRUM DE PRÓ-REITORES DE EXTENSÃO DAS UNIVERSIDADES PÚBLICAS BRASILEIRAS, 2012, p. 18)

A extensão, dentro do processo de formação, no período acadêmico propõe uma rede de ações que, construída pelos atores/autores envolvidos, torna-se uma intervenção transformadora. No entanto, conforme o fragmento acima, a ação extensionista deve ser capaz, através dos seus atores e autores, de garantir direitos e deveres, além de contribuir na transformação social. Isto é possível? Em que dimensões? Segue adiante uma experiência com o PEAC - Ação extensionista da Universidade Estadual de Feira de Santana-Ba.

\section{OS LABIRINTOS METODOLÓGICOS}

As ideias centrais desta produção conduziram o desenho desta investigação para uma abordagem qualitativa. $O$ método Pesquisa-Ação foi a referência e processo epistemológico que conduziu a pesquisa e a ação que está sendo apresentada nesta produção. A escolha deste método busca reafirmar o compromisso social e científico dos atores/autores envolvidos, oportunizados a compreender e vivenciar, numa ação transformadora da prática, a realidade em que vivem num diálogo permanente que deve se manifestar em todo o processo da investigação científica.

Destacamos, no entanto, que a ação de transformação desejada, não deve se confundir, ou ainda de maneira ingênua, ser entendida com uma mudança no sistema social. Como afirma Thiollent (2011, p. 50) "[...] é preciso deixar de manter a ilusões acerca de transformações da 
sociedade global quando se trata de um trabalho localizado aos níveis de grupos de pequena dimensão, sobretudo quando são grupos desprovidos de poder".

A metodologia da pesquisa-ação é recomendada para dinamizar a extensão universitária e, neste sentido, o objeto desta Pesquisa-Ação foi o PEAC - Programa Encaminhar Ação Cidadã, uma ação de extensão do Curso de Licenciatura em Educação Física da Universidade Estadual de Feira de Santana-Bahia (UEFS-Ba).

Dentre as ações deste programa está o Projeto Escola de Esportes. Nesta ação foram ministradas, de julho a dezembro de 2013, aulas de iniciação esportiva na quadra de esportes da Universidade Estadual de Feira de Santana/BA com 110 adolescentes de 9 a 14 anos. Estes moradores dos bairros circunvizinhos a esta instituição.

Para este artigo traremos apenas as considerações obtidas a partir das entrevistas e da análise do diário de bordo numa tentativa de constituir um discurso síntese sobre as considerações dos bolsistas envolvidos nesta ação. Esta síntese foi realizada a partir das adaptações realizadas ao método de Análise do Discurso do Sujeito Coletivo (LEFEVRE; LEFEVRE, 2003).

\section{PROJETO ESCOLA DE ESPORTES DO PEAC: REFLEXÕES DA PESQUISA E DA AÇÃO - ANÁLISE E DISCUSSÃO DOS RESULTADOS TECENDO OS (EN) CAMINHAMENTOS.}

Orientados pela fundamentação proposta por esta metodologia, ressaltamos o nosso intenso envolvimento como pesquisadores e interventores (atores e autores) nas ações do PEAC, estando, portanto, longe de neutralidades e, portanto, engajados em defender as causas e propor alternativas para solucionar as dificuldades identificadas.

É possível identificar nas ações que serão apresentadas e discutidas adiante, com algumas adaptações necessárias e possíveis em processo de pesquisa não linear, as etapas necessárias sugeridas por Dionne (2007) e Thiollent (2011) que orientam os caminhos para 0 desenvolvimento da Pesquisa-Ação.

\section{1 A primeira etapa: Identificando a Situação (percursos iniciais da investigação e da ação)}

Em análise ao primeiro relatório (diário de bordo) produzido pelo grupo de professores e estudantes responsáveis pelo desenvolvimento do programa, confirma-se, pela oralidade transcrita no documento, que os parâmetros que nortearam as primeiras ações do PEAC, foram frutos de construção coletiva, com a participação da comunidade universitária e representantes da sociedade em geral.

Dos discursos individuais extraídos destes registros pode ser destacado o pedido de socorro da comunidade circunvizinha da UEFS para que ações educativas sejam realizadas. Contudo, em paralelo identifica-se a preocupação da comunidade universitária ao sinalizar as limitações de uma instituição de ensino superior, em todas as dimensões, mas, especialmente nos aspectos estruturais e financeiros, para suprir as diversas carências sinalizadas. Estava estabelecido aí o primeiro grande desafio: como propor ações de transformação da realidade apresentada, tanto pelo olhar da comunidade circunvizinha (carência, criminalidade, ausência de políticas públicas), quanto pelo olhar dos representantes da UEFS (especialmente limitações 
estruturais, materialização de proposta pedagógica crítica e transformadora para o ensino do esporte).

As problemáticas foram identificadas pelos grupos e, assim, o próximo passo seria tomar as decisões. Com esta intenção surgiu a concepção do PEAC e o interesse em desenvolvê-lo em uma ação piloto, um projeto de extensão com vistas a se tornar ou a propor uma política pública, mas, especialmente, com o propósito de vivenciar o esporte de cunho educativo junto com uma comunidade carente de práticas corporais desta natureza.

\subsection{A segunda e a terceira etapa: Definição dos objetivos e da ação e o planejamento metodológico da pesquisa e da ação}

A partir da realidade identificada, alinhado com os parâmetros metodológicos da Pesquisa-Ação, perseguindo um "duplo objetivo, que é o de modificar uma dada situação e, ao mesmo tempo, o de enriquecer o conhecimento" (DIONNE, 2007, p. 44), foram traçados os objetivos para o programa.

Periodicamente em seminários, reuniões planejamento interno, encontro com representantes da comunidade, familiares sempre surgiam debates que giravam em torno de algumas temáticas complexas, entre elas: a) a temática da proposta pedagógica para o ensino do esporte (exemplo: educar através do esporte para a cidadania e/ou garantir os conteúdos técnicos e táticos para o esporte?) e b) a temática sobre concepção de extensão universitária: transpor os muros da universidade com conhecimentos acadêmicos para uma transformação social é possível, mesmo com a realidade social identificada?

\subsection{A quarta e quinta etapa: a realização da Escola de Esportes - a análise e verificação de resultados}

Com o objetivo inicial de acolher as famílias e alunos, promovendo atividades de integração, troca de saberes e apresentação de questões administrativas o grupo PEAC articulou o primeiro Seminário Central. Algumas das principais tarefas deste seminário central, incluindo aí o papel dos pesquisadores proposto por Thiollent (2011, p. 68), foram:

1. Centralizar informações provenientes das diversas fontes e grupos;

2. Buscar soluções e definir diretrizes de ação;

3. Colocar à disposição dos participantes os conhecimentos de ordem teórica ou prática para facilitar a discussão dos problemas;

4. Em estreita colaboração com os demais participantes, conceber $e$ aplicar, no desenvolvimento do projeto, modalidades de ação.

Sabíamos, desde os primeiros diálogos com a comunidade, da condição social desfavorável de muitas das famílias do entorno da UEFS (moradores dos Bairros atendidos). Algumas destas dificuldades foram novamente identificadas durante a realização deste primeiro seminário central e trouxeram algumas experiências aos acadêmicos bolsistas antes mesmo da intervenção nas aulas de esporte com os/as alunos/as.

Uma das bolsistas do programa, em entrevista, ao ser perguntada sobre a contribuição do programa na formação cidadã dos alunos relembrou fatos sobre este momento inicial: 
O primeiro momento acho que eu nem falo dos meninos apenas, falo das famílias, das mães, dos pais, dos irmãos que foram fazer o cadastramento [...] então assim a primeira intervenção cidadã de fato e que mais me marcou foi dona Dora (nome fictício). Ela não sabia escrever, ficou com vergonha de falar que não sabia. Ela perguntou como ela assinaria aquilo ali? Não a senhora pode assinar, a senhora coloca a digital, eu falei para ela. Mas a gente não tinha a esponja, eu lembrei que podia pintar a mão dela com a caneta e ela colocar a digital. Aí eu pintei o dedo dela, ela colocou a digital. Aí ela falou assim: a primeira pessoa que fez assim, em outros lugares eu não posso assinar, eles não deixam também [...] que bom que você fez isto e me abraçou. Foi simples, mas, bem marcante este processo (Bolsista 1).

Neste seminário central descortinava-se na academia e, em especial para os futuros professores, um mundo real. Ao encontrarmos nossos vizinhos tão próximos geograficamente, mas tão distantes aos nossos olhos e ações humanas, percebemos que as questões culturais, sociais ali imbricadas não poderiam ser descartadas. Ao contrário, devem fazer parte do processo que acompanha todos os fenômenos complexos e, diversas vezes, contraditórios.

\subsubsection{As aulas na Escola de Esportes: Educação Cidadã e/ou esportiva?}

$\mathrm{Na}$ realidade dos/as alunos/as do PEAC, a ausência da família, a aproximação com a criminalidade e o processo de educação básica escolar deficiente, que, em geral, produz os analfabetos funcionais, indicavam que os poucos avanços conquistados com a Escola de Esportes poderiam e deveriam ser valorizados.

As ações que se materializavam nesta realidade conflitante e desgastante encontram, nas imagens fotográficas, nos registros escritos etc. vozes e expressões dos sujeitos envolvidos a possibilidade de identificar contribuições significativas e que podem ser destacadas nas respostas dos bolsistas entrevistados.

Em entrevista, um dos bolsistas estabelece inicialmente o seu entendimento da importância dos meninos (alunos do PEAC) terem conquistado um espaço na UEFS e ainda o cuidado dos educadores com o processo afetivo. O PEAC possibilitou "uma formação cidadã para eles, para formação não só do caráter esportivo, mas alguém preocupado em saber como eles estão" (Bolsista 1).

A bolsista (2) inicia sua resposta relatando um fato com uma aluna, uma relação inicialmente conflituosa. De maneira simples relata o comportamento de uma menina durante as aulas do projeto, inclusive menciona a necessidade da parceria com a família para contribuir com este processo de formação e como as questões éticas/morais e afetivas estão sempre presentes no exercício docente.

"Teve um momento que ela não deixou eu dar aula, eu falei tá suspensa da aula. No outro dia ela trouxe várias flores e começou a chorar no canto. Ela chorou e eu chorei do lado dela" (Bolsista 2). A própria fala dos Bolsistas (1 e 2) transcrita abaixo revela o que para eles era a importância do programa na vida dos jovens envolvidos.

[...] E o fato deles se acostumarem a está na Universidade [...] A universidade está plantada na comunidade deles, mas, eles não tem vínculo com isso [...] um elefante branco uma coisa para outras pessoas e não para eles. 0 fato deles estarem se acostumando a estarem aqui pode abrir possibilidades diferentes para eles, acho que isto é importante nesta questão (BO 1). 
[...] a gente tá trabalhando agora no PEAC os planejamentos para organizar dentro daquele dia, para além do esporte, não era só este processo do esporte pelo esporte, o esporte enquanto uma ação cidadã de fato (BO 2).

Estes comentários expressam bem que o espaço de aula ia se tornando um ambiente, especialmente para os bolsistas, um espaço de formação e compreensão das dimensões educativas e cidadã do esporte na vida dos/as alunos/as da Escola de Esportes.

Ao longo dos encontros pedagógicos de planejamento e organização das aulas de esporte, aspectos críticos e reflexivos sobre a contribuição do mesmo na formação de sujeitos sempre esteve presente, inclusive a preocupação de como o esporte era tratado dentro da formação acadêmica.

Neste sentido, uma das bolsistas em entrevista sinaliza que "[...] as aulas no curso são muito distintas do esporte. Separadas do esporte em si. Não focava tanto como se deve [...] tem o trato pedagógico distinto, tem a parte marxista de fato, tem a parte da fisiologia e 0 esporte fica um tanto esquecido" (bolsista 2).

Nesta descrição a bolsista revela um claro discurso antagônico, de um lado os que fazem a crítica ao esporte 0 associando a uma produção capitalista, colocando-o em segundo plano ou, em atitudes mais extremas, negando-o através de discursos panfletários que travam apenas uma batalha: o esporte x justiça social e, do outro lado, numa visão do esporte como rendimento, da valorização dos aspectos fisiológicos da aptidão física. Claramente nota-se neste conflito a busca pela imposição ideológica que, como bem sinalizou a bolsista, deixou o esporte um tanto esquecido e, especialmente, uma formação no ensino superior cheia de lacunas e deficiências no conhecimento sobre e para o ensino do esporte.

O Esporte que temos não é apenas fruto do capitalismo inglês, ele também é atravessado pela cultura indígena, africana, asiática, pela cultura do jogo/brincadeira de rua, por rituais etc., entretanto, na conjuntura atual, encontra-se subordinado aos valores intrínsecos no modelo de sociedade do esporte moderno que tem se revelado nefasto. $O$ que fazer então? Negar o esporte? E as suas dimensões educativas, tática, técnicas? E suas ludicidades vivenciais?

Dificilmente teremos a sociedade do século XV, XVI ou XVII. Novas tecnologias, novas descobertas, diversidades mil nos fazem únicos e diferentes a cada segundo. $O$ Esporte mudou, transformou-se, assim como a sociedade que vivemos atualmente. Devemos estabelecer a crítica ás mazelas do esporte moderno na tentativa de superá-las e valorizar as novas produções humanas (outras modalidades esportivas, outras formas de jogar, outras regras, outros adversários) que nos ajudam a criar e recriar, o mundo que vivemos.

Estaria o PEAC dentro e através da UEFS se configurando como um espaço de resistência? De estímulo ao desenvolvimento da cidadania? A identificação de direitos e a socialização novos saberes? Oportunizando o aprendizado sobre esporte?

\subsubsection{Extensão universitária. Transpor os muros da universidade pode ser até fácil, difícil é lidar com a realidade encontrada. As pedras no caminho}

Em entrevista ao final das aulas do Projeto Escola de Esportes solicitamos aos bolsistas uma avaliação geral do programa, especialmente o projeto escola de esportes, e eles destacaram principalmente: "a importância do embasamento teórico, do planejamento para o 
ensino do esporte"; "a quantidade excessiva de crianças para dar conta"; "a aproximação com a realidade"; "o trazer eles para dentro da universidade"; "as grandes demandas administrativas"; "a ausência de mais bolsistas"; "A PROEX precisa rever a extensão na UEFS".

Estas foram algumas pedras no caminho, mas duas chamam especial atenção e estão entrelaçadas: a) a concepção de esporte no ensino superior e na sociedade em geral, que tratamos como mais êmfase anteriormente e b) a problemática da extensão universitária, na qual avançaremos a seguir.

As fragilidades e as contribuições para um efetivo protagonismo destes estudantes/ bolsistas proposto em ações extencionistas estavam identificadas nas ações do PEAC. Numa extensão universitária, que "sob o princípio constitucional da indissociabilidade entre ensino, pesquisa e extensão, é um processo interdisciplinar, educativo, cultural, científico e político que promove a interação transformadora entre Universidade e outros setores da sociedade" (FÓRUM DE PRÓ-REITORES DE EXTENSÃO DAS UNIVERSIDADES PÚBLICAS BRASILEIRAS, 2012, p. 15) é quase desumano pensar em qualidade ideal na intervenção com o sucateamento das universidades públicas brasileiras e as precárias condições de estudo e trabalho dos seus estudantes e funcionários, respectivamente.

De fato questionamos (todo o coletivo que compõe o PEAC) diversas vezes, qual era então a função deste programa? Sem um respaldo estrutural adequado, sem recursos financeiros suficientes, com ausência de mais "braços" para contribuir e, talvez por isto, sem perspectivas de continuidade, não estaria aí caracterizado um assistencialismo?

Apesar de não ser um programa de governo sugerido, em sua concepção teóricoprática, pelo âmbito municipal, estadual ou federal, o PEAC, é uma forma de exercício do poder do estado (políticas nacionais da extensão universitária), uma modalidade de regulação de âmbito político que pretende interagir entre o estado e a sociedade, travando a luta pelos direitos, justiça social. Contudo, assim como toda ação de impacto local, apresenta limitações em perspectivas de continuidade, devido especialmente a falta de integralização com ações voltadas à saúde, emprego, educação etc. Para esta unidade acontecer devemos reconhecer que a intervenção direta do estado precisa acontecer.

Um Estado efetivo em suas intervenções econômicas e sociais não é apenas um Estado dotado com uma classe política responsiva, responsável e responsabilizável; é também um Estado dotado de recursos financeiros e materiais e de uma burocracia com capacidade de fazer uso competente desses recursos (FÓRUM DE PRÓ-REITORES DE EXTENSÃO DAS UNIVERSIDADES PÚBLICAS BRASILEIRAS, 2012, p. 12).

Este uso competente dos recursos mencionados direciona para a necessidade da existência de políticas públicas efetivas, que envolvam os gestores, os representantes de instituições e a comunidade em geral, uma ação colaborativa de respeito, cuidado com o ser humano, uma transformação social.

\section{CONCLUSÃO PARA NOVOS (EN)CAMINHAMENTOS}

Diante das limitações e possibilidades reveladas (ou não) ao longo da análise e discussões possíveis de serem aqui mencionadas, a proposta deste artigo foi a de apresentar uma síntese do resultado de uma pesquisa e de uma ação, fruto de uma dissertação de mestrado em educação. 
Neste sentido, o estudo apontou que o PEAC permitiu aos seus atores e autores produzirem, no campo teórico-prático, novos conhecimentos, inclusive propondo um novo olhar para ações extensionistas e a compreensão do esporte, especialmente em projetos sociais.

As teias que constituíram toda a construção e desenvolvimento do Projeto Escola de Esporte oportunizaram uma aproximação crítica com a realidade diversa e difícil, identificada junto à comunidade moradora dos bairros circunvizinhos à UEFS, com as professoras, alunos/ as e coordenação das Escolas e bolsistas.

Muitos destes relatos não puderam ser aqui transcritos, contudo, ficou claro que a luta pela justiça social é, muitas vezes, desigual. Entretanto, não podemos deixar de oportunizar ações de extensão como o PEAC junto à comunidade, mesmo considerando que as crianças atendidas, ao retornarem para suas casas estão, em geral, imersas numa realidade dura, desumana e injusta, o que permite interpretar que os valores aprendidos nas aulas de esporte podem não ser suficientemente capazes de transformar de maneira significativa as suas vidas.

Devemos considerar, por mais que dura que seja a realidade, que a mesma criança que arremessa uma bola de handebol em direção as traves/redes na quadra de esportes marcando um belo gol, pode usar as mãos para tirar uma vida humana. Isto porque o gol marcado na infância nesta quadra, não leva em conta (e nem poderia isoladamente) romper e superar as injustiças na qual aquela criança continuou submetida. Contudo, felizmente, esta realidade não está determinada e as transformações possíveis já são um sinal de esperança. O futuro se faz na construção, numa atitude otimista (PRIGOGINE, 2003).

Mesmo com este olhar otimista, reconhecendo que "[...] carvalhos centenários desenvolveram-se a partir de bolotas ridiculamente minúsculas" (BAUMAN, 2013, p. 28) se quisermos, enquanto educadores, ampliar os impactos de nossas ações e melhorar as condições de atuação dos envolvidos em espaços educativos devemos, também, produzir espaços de resistências em múltiplas dimensões e espaços (inclusive nas macroestruturas políticas). Devemos reconhecer que muitas escolhas e situações que vivemos no PEAC passaram por decisões políticas, o que potencializa ou limita as transformações que aconteceram ou poderiam ter acontecido em nossos educandos.

O PEAC como o próprio nome diz é um programa onde seus atores e autores se propõem a encaminhar ações cidadãs e, nesta perspectiva, pensamos que o mesmo ofereceu, a partir das vivências, lanternas para as travessias dos sujeitos envolvidos no processo. Desta forma, o grupo PEAC não se posicionou como salvador de todos os problemas e, com esta atitude, reconheceu as suas limitações enquanto uma ação extensionista.

Os caminhos possíveis, a partir do contexto investigado, foram sinalizados. Os registros desta navegação apontam os locais de águas agitadas, sugerem alternativas, e especialmente, revelam os aprendizados e as conquistas possíveis.

Durante as ações da Escola de Esportes compreendemos que, sem as condições adequadas e uma ação integralizada entre os diversos saberes humanos e suas diversas representatividades, as proposições de políticas públicas ou ações extensionistas, poderão se tornar na prática um assistencialismo cínico, disfarçado e/ou omisso, blindados por teorias salvacionistas e muros de instituições que, em geral, estão representadas por indivíduos corrompidos, cansados, manipulados ou desinteressados a propor, (in)tencionalmente, mudanças sociais estruturantes e possíveis. 
As ações no nível local, como o PEAC, por exemplo, representam possibilidades importantes de reinvenções, de relações/aproximações e proposições e o esporte é sim um excelente instrumento pedagógico para gerar transformações. Entretanto, o poder destas transformações é obviamente limitado, mas, ainda assim uma possibilidade de resistência e, assim sendo, um espaço preservado de dignidade humana.

Consideramos que $O$ PEAC propõe ou retroalimenta um debate importante ao considerar que as discussões teóricas sobre o Esporte na área de Educação Física, de forma geral, ainda não deram conta de materializar, nos diversos espaços de atuação do professor, um ensino de esporte que o compreenda como uma orgânica manifestação cultural.

Atitudes e pensamentos maniqueístas, através e sobre o esporte, demonstram, dentre várias outras, uma situação que se agrava cada vez mais: a ausência de diálogo intenso entre o saber científico e o saber popular, que, muitas vezes, é negada nos principais centros de formação (especialmente as universidades).

É necessário algo diferente. E a isto se propôs o PEAC - Escola de Esportes. Desenvolver, junto com à comunidade e através desta, ações vivenciais que estão para além de fazer apenas a crítica (negando as práticas esportivas) ou repetir gestos esportivos de maneira alienada.

Esta posição rompe com a compreensão de uma minoria, por muitas vezes, oportunista, assistencialista, vendedora de ilusão, que, em geral, utiliza o esporte apenas pelas suas possibilidades econômicas ou como argumento teórico panfletário, desconsiderando, assim, os seus jogadores, usando-os como peças descartáveis em um tabuleiro social de interesses quase sempre produtivistas e alienantes.

Por diversas vezes nos deparamos com uma realidade, dentro e fora da universidade, que vem produzindo sofrimento, concentrando pobrezas, incentivando a destruição da natureza, valorizando o consumismo. E numa atitude, por vezes contraditória, os centros de formação pelo país cria mecanismos buscando, em geral, apenas ampliar o número de artigos registrado no lattes de docentes (valorizando apenas os aspectos quantitativos), ou ainda ampliando 0 número de teses e dissertações nas bibliotecas que, em geral, deixam poucas contribuições e melhorias na vida da sociedade em geral. O PEAC propôs um movimento que ressalta a importância do conhecimento intelectual, contudo, numa construção vivencial com os seres humanos envolvidos no processo, considerando também a importância do conhecimento do ser humano (MORIN, 2002).

Apesar das contradições e enfrentamentos, ainda assim esperamos (construindo e vivenciando) dias melhores inspirados nas esperanças que renascem na natureza, nos seres humanos e nas quadras/campos de esportes pelo nosso imenso Brasil.

Propomos que se recomece o jogo, contudo, com novos sujeitos, novas estratégias, novas teorias, novas práticas. Só que agora ainda mais fortalecido no pensar e agir em prol de um mesmo desejo: a transformação humana.

Neste sentido, "[...] eu prefiro ser esta metamorfose ambulante [...] do que ter aquela velha opinião formada sobre tudo" (RAUL SEIXAS). Uma metamorfose onde a vida fecunda 0 pensamento e as ações, e estes, fecundam a vida. 


\section{REFERÊNCIAS}

ARAÚJO, Miguel Almir Lima de. Os sentidos da sensibilidade: sua fruição no fenômeno do educar. Salvador : EDUFBA, 2008.

BAUMAN, Zygmunt. Sobre educação e juventude: conversas com Riccardo Mazzeo/Zygmunt Bauman. Tradução de Carlos Alberto Medeiros. Rio de Janeiro: Zahar, 2013.

CONDÉ, Mauro Lúcio Leitão. De Galileu a Armstrong: as várias faces da lua. Cronos, Revista de História, Pedro Leopoldo, n. 5, p. 42-56, jun. 2002.

DIONNE, Hugues. A pesquisa-ação para o desenvolvimento local. Brasília: Liber Livro, 2007.

FÓRUM DE PRÓ-REITORES DE EXTENSÃO DAS UNIVERSIDADES PÚBLICAS

BRASILEIRAS, 2012, Manaus. Política Nacional de Extensão Universitária. Disponível em: $<$ http://www.renex.org.br/documentos/2012-07-13-Politica-Nacional-de-Extensao.pdf>. Acesso em: 20 dez. 2013.

FORQUIN, Jean-Calude. Escola e cultura: as bases sociais e epistemológicas do conhecimento escolar. Porto Alegre: Artes Médicas, 1993.

KUNZ, E. Transformação didático-pedagógica do esporte. 4. ed. ljuí: Unijuí, 2001.

LEFEVRE Fernando; LEFEVRE Ana Maria. 0 discurso do sujeito coletivo: um novo enfoque em pesquisa qualitativa (desdobramentos) Caxias do Sul: EDUCS, 2003.

MELO, Victor Andrade et al. Pesquisa histórica e história do esporte. Rio de Janeiro: 7 letras, 2013.

MORIN, Edgar. Os sete saberes necessários à educação do futuro. 3. ed. São Paulo: Cortez, 2002.

ORTEGA ESCOBAR, Micheli. Jogo e esporte na cultura corporal. In: ORTEGA ESCOBAR, Micheli et al. Manifestações dos jogos. Brasília: Universidade de Brasília, 2005. p 11-45.

PRIGOGINE, llya. O Fim da Certeza. In: MENDES, Candido (Org.). Representação e complexidade. Rio de Janeiro: Garamond, 2003. p 47 -68.

SAVIANI, Dermeval. Escola e democracia: teorias da educação, curvatura da vara, onze teses sobre a educação política. 40. ed. Campinas, SP: Autores Associados, 2008.

SILVA, Maria Cecília de Paula. Do corpo objeto ao sujeito histórico: perspectiva do corpo na história da educação brasileira. Salvador: EDUFBA, 2009.

SOARES, Carmem Lúcia et al. Metodologia do ensino da Educação Física. São Paulo: Cortez, 1992.

SODRÉ, Muniz. Reinventando a educação: diversidade, descolonização e redes. Petrópolis, RJ: Vozes, 2012.

SOUZA JÚNIOR, Marcilio et al. A cultura corporal em questão. Revista Brasileira de Ciências do Esporte, Florianópolis, v. 33, n. 2, p. 391-411, abr./jun. 2011.

THIOLLENT, Michael. Metodologia da pesquisa-ação. 18. ed. São Paulo: Cortez, 2011. 